\title{
Ambiguity and Final Choice: Reader's Response in A Streetcar Named Desire
}

\author{
Liang Zhang \\ Teachers' College of Beijing Union University, No.5 Wai Guan Xie Jie Street, Beijing 100011, China
}

\begin{abstract}
Applying Stanley Fish's Reader-response criticism, the article analyses the two protagonists, Blanche and Stanley, in Tennessee Williams' A Streetcar Named Desire from reader's perspective. The article holds that readers in appreciating the play are divided into two sides: one showing their sympathy and support on Blanche, while the other standing aside with Stanley. However, their attitudes towards their "heroine" and "hero" are not always certain and firm. It is caused by the ambiguities created by Williams for misleading readers in their appreciation. Until in the last scene do readers finally make clear these ambiguities and realize writer's true intention. The article also points out the reasons why Williams intentionally created ambiqutities in his most famous work.
\end{abstract}

Index Terms — reader- response criticism, ambiguity, final choice

\section{INTRODUCTION}

Since A Streetcar Named Desire premiered in 1947, it has always been regarded as Tennessee Williams' most charming play as well as the most controversial creation. For more than sixty years, it continually stimulates critics to interpret it from as many aspects as possible. Herbert Blau analyzed it from the post-modernist viewpoint; Kelvin observed Blanch as the prey of guilty, melancholy and hysteria, while Stanley as the representative of desire, social order and "the male genital"; Lionell Telly studied the history and fable factors existing in the play; Robert Ray employed modern Marxist theory into his analysis and concluded that Williams actually had abstract and dialect ideology in his mind. Almost all the existent theories were creatively and boldly used in the play's interpretation. Only one critical method seems to be ignored, that is, reader-response critical theory.

In the field of the literary criticism, the most significant change that has occurred is the movement from author to reader. In the disciplines of literary criticism, it was originally assumed that meaning resided with the author, then within the text. The shift in the locus of meaning continued under the influence of cultural pressures and meaning came to be seen as inhering in the reader. Here appeared the reader-oriented criticism. One of the most prominent reader-response critics is Stanley Fish. According to Fish, it is the reader that determines the shape of text, its form, and its content, and he claims that reader write text. Although critics generally think that Fish's theory is too radical, it is very meaning for Fish to emphasize reader's role in the interpretation of literary woks. As early as in fourth century, Aristotle had discussed the relationship between the tragedy and audience in his "The Poetics" and pointed out that the best effect of tragedy was to arouse audience's tears and purify their souls. Fish's theory greatly pushed literary criticism forward. He used the reader-response criticism in his early work "Surprised by Sin: the Reader in Paradise Lost", and firstly connected the author, text and reader together in the interpretation of literary works. Fish applied the phenomenological method in his work which focuses on what happens in reader's mind as he or she reads.

Enlightened by Fish's opinion, the article tries to interpret A Streetcar Named Desire with the phenomenological method, and discusses readers or audiences' response during approaching the play, the ambiguities occurred in the their mind and the their final choice confronting with these ambiguities.

\section{READER'S RESPONSE TO THE Two PROTAGONISTS}

Critics once quarreled around one question for a long time, that is, "who is the real protagonist of the play, Blanche or Stanley." The article holds that both of them are protagonists of the play. Williams actually intended a balance of power between Blanche and Stanley, and the action proceeded through clashes of these two opposites.

In the play, Blanche and Stanley are just like two competitors in the arena. The stage is their battlefield and readers or audiences are their spectators standing aside to see their performance, at the same time, readers are deciding their attitudes and giving out their response to the two "competitor". In the total eleven scenes of the play, the first ten scenes is the matching process. Blanche and Stanley get their own supporters and the readers are divided into two sides. One side believes Blanche and support Blanche, while the other side stands aside with Stanley, and shout encouragement for him. The article recognizes that Mitch and Stella are the two spectators in the play, from their attitude for the characters, the reader's response can be well illustrated.

A. Reader's Response to Blanche

Blanche came from Mississippi to New Orleans to go to her married sister for shelter. When the protagonist appeared, 
the initial question for reader is her identity. Blanche herself claimed that she was a teacher who took a leave from school. That's initial knowledge given by Blanche. But soon, through Blanche's conversation with Stella and Stanley, readers got more information. Blanche and Stella, the two sisters were born in the southern aristocracy that had got bankrupt. Blanche once married but her husband died. Blanche was not in good health, for she always tried to quiet her nerves by taking bath, and she's terribly upset. These information are enough to rouse reader's sympathy for Blanche, a widow in poor situation.

However, such a poor woman was bad treated by her brother-in-law, Stanley. When Stanley knew that Belle Reve was lost, Stanley doubted Stanley's word and brutally opened Blanche's wardrobe and checked it up. Especially when Stanley found Blanche's letters, he ripped off the ribbon and examined them without Blanche's permission. Blanche snatched them from him, and letters cascaded to the floor. "Everyone has something he won't let others touch because of their intimate nature", Blanche said, however, Stanley rudely touched her privacy and showed little respect for others. A woman confronting with the harm from a barbarous man appeared so weak and fragile that Blanche again got sensitive readers' sympathy. Some readers strongly support Blanche and showed their antipathy to Stanley for his barbarous, brutality and cruelty. Blanche's loyal party began to form.

At this moment, another key character to Blanche, Mitch appeared. Mitch was Stanley's intimate friend. Mitch was noticeably more sensitive than Stanley's other poker friends. Even in his first, brief snatch of conversation in Scene One, Mitch's more gentlemanly behavior stood out in contrast with the behavior of the other men. Through his first touch with Blanche, Mitch was immediately attracted by Blanche's unusual language, gesture, and special quality. In a sense, Mitch also became a loyal reader who held respect and love for Blanche. From Mitch's perspective, Blanche was a well-bred, well-educated and graceful woman. Mitch shameful said to Blanche: "I guess we strike you as being a pretty rough bunch."(1796), and "In all my experience, I have never know anyone like you."(1812). Mitch was always shy before Blanche; he admired Blanche and thought she was superior to him. When Blanche told him about her former husband, Mitch didn't dislike her; on the contrary, Mitch gave her sympathy and soon proposed to Blanche. Blanche not only gained Mitch's feeling but also that of some readers who supported her in her battle with Stanley.

However, her opponent, Stanley disclosed her secret. Not only "Dame Blanche" a disreputable resident of the Flamingo Hotel in laurel, but also she was fired from her teaching position at the high school for getting "mixed up with " a seventeen-year-old boy. Stanley's exposure was a bolt from blue foe readers. It is completely out of their expectation. Facing to the situation, some readers begin to adjust their attitude for Blanche. Some deserted Blanche and turned to Stanley, just as Mitch did. As soon as Mitch knew Blanche's sordid sexual past, he was both angry and embarrassed about the way Blanche had treated of him. When he arrived to chastised her, he stated that he felt he deserved to have sex with her, even though he no longer respect her enough to think her fit to be his wife. Mitch's attitude represented some reader's response to Blanche. For them, Blanche cheated their feeling and sympathy. However still, there are loyal readers who persist their original position and continually support Blanche. Although Blanche made mistakes, these readers still show sympathy on her, just as Stella did. When Stanley told Blanche's secret to her, she didn't dislike her sister, but worried about her: "Is Mitch through with her? She thought Mitch was going to marry her, what'll she do? What on earth will she do?" These sentences actually tell out reader's care about Blanche. Stanley's disclose of Blanche only cause part of Blanche's follower desert her, but it even rouses more hatred to Stanley and more sympathy for Blanche. Especially when Stanley raped Blanche in scene10, it finally illustrated Blanche's comments on Stanley: "He acts like animal, has an animal's habits!.... There's even something ---subhuman---something not quite to the stage of humanity yet! .... Something ape-like about him, ... And there he is, survivor of the Stone Age! .... Don't hang back with the brutes!" Yes, Stanley was but an animal that did beast thing to his sister-in-law, a poor woman. It vividly compared Blanche's civilization with Stanley's coarseness. From these words, Blanche finally became a protector of civilization and the loyal daughter of old south. For the readers with literary competence (the term proposed by Fish to refer to those readers who have certain literary knowledge), the scene of rape actually contained deep meaning: Fragile southern fair maiden was brutally raped by the northern worker, this southern belle with traditional merits such as being gentle, affectionate and graceful was raped by cruelty and cruelty of the modern society, she liked a lonely and helpless white moth being crushed into pieces by the world with full of carnal desire and brutish nature. What this incident signified is the unavoidable humane tragedy of culture of southern plantation in the industrialized process of the North. As a result, blanche finally won the hearts of these readers and became the Heroine in their minds.

\section{B. Reader's Response to Stanley}

As the article mentioned in the previous part, the play was full of conflicts between Blanche and Stanley, and each had their own supporters. Then, what's the other side of reader's response to their hero?

Reader's response to Stanley also began from his appearance on the stage. Readers got information about him from Stella: he was polish, once a Master Seargeant in the Engineers' corps, an ambitious man who liked the hard exercises such as bowling. Actually it was a typical image of a blue-collar immigrant. Generally speaking, common people will support woman when woman and man are in a conflict, no matter who is right. So, Stanley was not so likable person to reader at the start of the play. However, Stanley was not always in a disadvantaged state, he soon caught some readers' attention.

Although Blanche and Stanley were opponents, Blanche couldn't stop praising Stanley: "You're simple, straightforward and honest...." It was the fair commentary on Stanley. For some reader, Stanley was a man with true nature. He could call the compliments to a woman about their looking as "stuff", it from one part shows that he was frank 
and open which unavoidably caused some readers favorable impression.

When Stanley quarreled with Blanche about Belle Reve, it may also cause some rational readers' doubt: maybe Blanche really did tell lies and Stanley was somehow reasonable. Especially when author described some character weakness of Blanche in the play, some readers may more believe Stanley and stand with Stanley to object Blanche. When Stanley found Blanche was actually a prostitute, his former misbehavior to Blanche was thought reasonable and those readers with Stanley seem find the strongest weapon to fight back Blanche and approve Stanley as a wise and true man. Besides, those readers also find other good qualities of Stanley, such as his loyalty to his friend and his passion to his wife. He told Blanche's disgraceful past to Mitch, although Mitch misunderstood him for the moment, but he said that: "I'd have that on my conscience the rest of my life if I knew all that stuff and let my best friend get caught!"(1820) This sentence can easily touch those readers who already support Stanley.

Audience members may also see Stanley as an egalitarian hero in the play. Stanley possessed an animalistic physical vigor that was evident in his love of work, of fighting, and of sex. His family was from Poland, and several times he expresses his outrage at being called "Polack" and other derogatory names. When Blanche called him a "Polack," he made her look old-fashioned and ignorant by asserting that he was born in America, was an American, and could only be called "Polish." Stanley represented the new, heterogeneous America to which Blanche didn't belong, because she was a relic from a defunct social hierarchy. He saw himself as a social leveler and egalitarian, as he told Stella in Scene Eight.

Stanley's intense hatred of Blanche was motivated in part by the aristocratic past Blanche represented. He also saw her as untrustworthy and did not appreciate the way she attempted to fool him and his friends into thinking she was better than they were. Stanley's animosity toward Blanche manifested the conflict between two cultures, two worlds.

At the fierce moment of their battle, the rape scene happened, Stanley's image in his loyal reader's mind was unavoidably damaged. No matter how fierce the conflict was between Blanche and him, he should not rape his sister-in-law, and it was inhuman deed. So, Stanley's followers began to query him: Maybe Blanche's commentary on Stanley had some reasonable points.

From the analyses, we see that Williams successful lead readers into two opposite positions. Two sides represent different attitude for the protagonists. Some readers regard Blanche as the haggard and frail southern belle who degraded because of the evils in materialist world, and take Blanche as the protector of the waning north culture; while others insist that Stanley represent the new social order of modern American as a contrast to the decayed gentility of Blanche's southern manners. However, the two sides of readers are not sure whether their choice is right or wrong. That's because they are influenced by the uncertainties coming from the text.

\section{AMBIGUities IN THE PlAY}

In Fish's reader-response theory, there are two types of readers: one is informed -reader, which refers to the common appreciators of the literary woks; the other type is the reader with literary competence that has certain reading experience and literary knowledge. In A Streetcar Named Desire, Williams caused confusion in the mind of both informed-readers and literary-competence readers to a different extent.

To informed-reader, the suspicion is Williams's ambiguous description of Stanley and Blanche's complex characteristics. Under Williams' pen, there seemed no hero and heroine in the play. Stanley and Blanche were rounded characters; both owned the positive and negative aspects. About Blanche, on one hand, she gained reader's sympathy, on the other hand, readers will find that she did have character weakness, such as hypocritical, snobbish, a little neurotic and so on. She lived in a perpetual panic about her fading beauty, her manner is dainty and frail, and she took a wardrobe of showy but cheap evening clothes, all these details reflected her character weakness. Besides, readers can also find she was not so graceful as she displayed. For example, one time, she talked with Mitch about keeping her reputation, but another time, she flirted with a young man who called at door. This contrast reflected that how contradict between her inner mind and surface behavior. It is no wonder that some critics regard Blanche as a self-degraded woman, and a contradict body between inner desire and outer oppression. About Stanley, some readers took him as a true man, honest, loyal to friend and family, ambitious in work, but his cruelty, animal impulse can't be ignored, such as beating Stella, raping Blanche. However, Williams seemed provide some excuses to set Stanley free. For example, Blanche was a sudden visitor for Stanley and Stella, her appearance indeed brought much inconvenience for Stanley's normal life, Blanche herself also realized this point: "But there is no door between the two rooms, and Stanley--- will it be decent?"(1779) The answer was negative. As a man like Stanley, he would not also anyone to set a stone between he and his wife, especially a woman who always wanted to bring his wife away from him. Besides, although Blanche was lady with fading beauty, she still attracted men, Mitch was a good example, and Stanley was also no exception. Face to these ambiguous descriptions in the play, readers felt a loss.

For those readers with literary-competence, they would analyze the Conflict between Blanche and Stanley from a deeper meaning. To those readers who regard Blanche as the bodyguard of civilization, the conflict between Blanch and Stanley are the conflicts of two kinds of civilization. What Blanch represented is the old culture of the South, this tradition required woman chaste, pious and submitting to husband, to a certain extent, it responded to Victorian era's requisition for woman. But careful reader will find that Blanch seem to be attracted by Stanley, the gravedigger of the old South.

In Act 1, Blanche spied on Stanley's biceps stealthily, frightened as well as attracted; In Act 2, she provoked and sprayed the perfume on Stanley, and then invited Stanley to help her to tie the button behind of dresses; Blanche told 
Stanley half flatter and half serious: "My sister has married a man! " Another evidence is Blanche's practical conversation with Stella: "Maybe he's what we need to mix with our blood now that we've lost Belle Reve." (1790) This is obviously a kind of approval to Stanley. Blanch was looking for last outlet for family that had already declined, because the old South in morbid state couldn't maintain without pouring into the other style of blood, and Stanley was exactly the blood of that style that they needed. The appeal from Stanley that couldn't be resisted constructed the mutually exclusive conflict between she and Stanley; this plot will unavoidably weaken her image of as the defender of the old southern.

Uncertain discription also exists in the portrayal of Stanley. Ellia Kazan, the director of the 1959 film "A streetcar named Desire" refined Stanley's personality as indulging in material comfort and being cruel, which no doubt represented understanding to Stanley of a great deal of reviewers. However, Williams also created uncertainty in Stanley. It was displayed mainly in Act 3. When Stella put an end to the poker game and ordered the other men out of the house, Stanley hit her. Stella and Blanche then retreated upstairs to Eunice's apartment. Stanley called up to the apartment above, to Stella, in some kind of half-animal desperation, he cried in night like a baby. Stanley's behavior in one part showed his soft and kind aspect in human nature that weakened his cruel image to a certain extent and gained reader's understanding and sympathy. And another point that had been mentioned is that, Blanche lived in the house with one bedroom influenced the normal life of couple, which can also be taken as the excuse for his raping Blanche.

All above-mentioned uncertainties sometimes push forward readers, but sometimes draw them backward. Readers were confused for William's intention, and the final choice should be made soon to make clear these ambiguities.

\section{Final Settlement of the Ambiguities And Author’s True Intention}

George Blaire once said that when readers were misled by the text and felt a loss in author's narration, readers could try to find author's hiding voice in the works. In many literary works, there exists a narrator that plays a role as mediator between author, text and reader. Since there was no narrator in A Streetcar Named Desire, readers have to find Williams' true voice when confronting to these ambiguities. In the last scene, readers can easily realize Williams' attitude toward Blanche and Stanley.

Readers are successfully led into Williams's trap, and then, it's time to solve these problems. In the last scene, Williams stopped his uncertain description as in the previous ten scenes; instead, he finally gave a certain image of the two protagonists, especially the decisive portrayal of Stanley.

In his competition with Blanche, Stanley took the final stabs at Blanche, destroying the remainder of her sexual and mental esteem by raping her and then sending her to an insane asylum. In the end, Stanley's down-to-earth character proves harmfully crude and brutish. His disturbing, degenerate nature was fully evident after he raped his sister-in-law. Stanley shows no remorse for his brutal actions. When the doctor and nurse tried to take Blanche away, Stanley continually laughed at Blanche: "You left nothing here but split talcum and old empty perfume bottles, unless it's the paper lantern you want to take with you." The mad Blanche was ill treated by the nurse, While Stanley stood aside and peered at all this. It was a vivid description. Compared with Stanley, winner's happiness, Blanche's miserable situation roused more sympathetic feeling from readers. In the end of the play, the poor Blanche blindly allowed herself to be led away by a kind doctor, ignoring her sister's cries. Blanche's final image unavoidably gains the sympathy of all the readers. Blanche once said: " Some things are not forgivable, deliberate cruelty is not forgivable"(1832). Stanley lost the basic sympathy of human beings, and he also lost readers' heart.

As the article has analyzed, Mitch and Stella actually were also readers as well as us. At the end of the play, they made their final choice in this struggle between Stanley and Blanche. Their attitudes were really that of the general readers. Mitch regretted his formed deeds to Blanche. When he realized Blanche was going to be sent to an insane asylum, he fought with Stanley and sobbed, maybe for Blanche's tragic end, and also for his ever misbehavior to Blanche. In Kalan's 1951 film, it ended with the impression that Stella would take her baby and leave Stanley. It was Kazan and Williams' common decision that "the rapist would not go unpunished." It hinted that the nominal winner, Stanley, had also lost, in that the relationships he valued most---those with his wife and his best friend.

These final details given by Williams clearly gave readers his own choice in the struggle between Stanley and Blanche, that is, despite her contradictions, dishonesty, inconsistency, Blanche was still a sympathetic, if not entirely likeable, character. Williams himself once commented that “... when I think about her, Blanche seems like the youth of our hearts which has to be put away for worldly considerations: poetry, music, the early soft feelings that we can't afford to live with under a naked light bulb which is now." Even though her faults are plain to see, Blanche still commands pity. Williams thought that this pity was an important element of the play. In a letter to Elia Kazan, the first director of Streetcar, he answered a question that Kazan had put to him, saying, and "I remember you asked me what should an audience feel for Blanche, certainly pity. It is a tragedy with the classic aim of producing a catharsis of pity and terror and in order to do that, Blanche must finally have the understanding and compassion of the audience." From these, readers can have a clear idea of Williams feeling for Blanche, reader's confusion in mind finally was solved under the help of Williams, and they also made the same choice with the writer.

\section{CONCLUSION}

Concerning the reason why Williams created so many ambiguities in A Streetcar Named Desire, critics have been 
discussing it for quiet a long time but in vain. Two opinions remains cores of the issue.

The first is that Williams' ambiguous descriptions are actual reflections of his inner conflict. Under Williams's portrayal, Blanche was molded as an immortal woman; a fragile southern beauty whose pathetic last grasp at happiness was cruelly destroyed. She was the last spokeswoman and loyal daughter of the old south. While, Williams himself was also the loyal son of the old south. He once said that the reason he took up the writing career was due to his deep love to south. According to Williams, in south, there owned a life style that was full of charm, gracefulness and civilization, it was not a society based on money. However, it could not prevent its descending from the historical stage. Blanche, as the last representative of the old south, could not either avoid her final tragic destination. In Williams' mind, Blanche was exactly the proper image of his old south. Although he could not save it, he paid his complete sympathy on it. As a result, after a long struggle in writing the play, Williams finally make clear the ambiguities and showed his sympathy on Blanche.

The other opinion about Williams' ambiguous writing is related to his real life at the time. Some critics hold that Williams really reflected his life style into the play. The conflict and struggle between Blanche and Stanley was the true representation of the relationship between he and Pancho Rodriguez, a man who deeply attracted Williams when he was writing the play. These critics think that, in a sense, Williams was Blanche, while Pancho was Stanley. Williams felt deep pain for his improper relationship with Pancho, he knew that this life must lead to a destruction, but he found no way to get rid of these messes in his life. He was caught in a deep conflict that unavoidably reflected in the play. Finally, he chose s destructive end for Blanche, it also represented Williams's own prospective for life. On one hand, he felt guilty of this degrading life but could not get rid of it, on the other hand, he could not stop showing pity on himself. So, Williams' real life experience was authentically displayed in the play.

No matter what is the real cause of Williams' ambiguities in the play, as for the artistic creation, Williams was succeeded. In the play, he implied artistic techniques to intentionally cause readers' different reaction and confusion to the main characters, and only gave them the answer at the end of the play. William successfully used reader-response theory to stimulate reader's active participation in the play, at last, the harmony among author, play and reader was achieved. From this aspect, we can say that Williams deserved to be the outstanding playwright, just as Garson Kanin claimed: " Tennessee Williams was the best, and A Streetcar Named Desire was his best."

\section{REFERENCES}

[1] Alexander W Allison, Arthur. J. Carr. \& Arthur M. Eastman. (1990). Masterpieces of the Drama (the fifth edition). New York: Macmillan Publishing Company.

[2] Mack, Maynard \& Bernard. M.W. (1992). The Norton Anthology of World Masterpiece (the sixth edition). New York, London: W.W. Norton \&Company.

[3] Nina Baym, Wayne Franklin, Phillip F. Gura \& Jerome Klinkowitz. (eds.) (2011). The Norton Anthology of American Literature (the eighth revised edition). New York, London: WW Norton \& Company.

[4] Roudane, Matthew C. (1999). The Cambridge Companion To Tennessee Williams. Cambridge: Cambridge UP.

[5] Wen, anchu. (1998). Reader-response criticism: theory and Practice. Beijing: China Social Science Press.

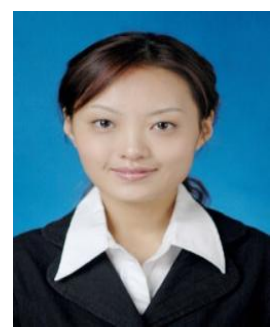

Liang Zhang was born in Henan Province, People's Republic of China in 1981. She finished her MA in English Language and Literature in Wuhan University, China in 2006.

She is currently a professor of Teachers' College of Beijing Union University. She has taught intensive English and advanced English for nearly seven years, and won quite a number of prizes in teaching competitions. She has also supervised a large number of BA dissertations in literature. Her major research interests are TESL and British \& American literature. 